Submission to "Special issue: New Materials for Nuclear" in the Journal of Nuclear Materials

\title{
Detection and quantification of solute clusters in a nanostructured ferritic alloy
}

M. K. Miller ${ }^{1}$, D. Reinhard ${ }^{2}$ and D. J. Larson ${ }^{2}$

${ }^{1}$ Center for Nanophase Materials Sciences, Oak Ridge National Laboratory, Oak Ridge, TN 37831-6139

${ }^{2}$ CAMECA Instruments, Inc., 5500 Nobel Drive, Madison, WI 53711

Corresponding author contact information:

Dr. Michael K. Miller

Center for Nanophase Materials Sciences,

Oak Ridge National Laboratory, P.O. Box 2008, Oak Ridge, TN 37831, USA

E-mail: millermk@ornl.gov

Phone: 8655744719

E-mails of coauthors:

David.Reinhard@ametek.com

David.Larson@ametek.com

This submission was sponsored by a contractor of the United States Government under contract DE-AC05-00OR22725 with the United States Department of Energy. The United States Government retains, and the publisher, by accepting this submission for publication, acknowledges that the United States Government retains, a nonexclusive, paid-up, irrevocable, worldwide license to publish or reproduce the published form of this submission, or allow others to do so, for United States Government purposes. 


\begin{abstract}
A series of simulated atom probe datasets were examined with a friends-of-friends method to establish the detection efficiency required to resolve solute clusters in the ferrite phase of a 14YWT nanostructured ferritic alloy. The size and number densities of solute clusters in the ferrite of the as-milled mechanicallyalloyed condition and the stir zone of a friction stir weld were estimated with a prototype high-detectionefficiency $(\sim 80 \%)$ local electrode atom probe. High number densities, $1.8 \times 10^{24} \mathrm{~m}^{-3}$ and $1.2 \times 10^{24} \mathrm{~m}^{-3}$, respectively of solute clusters containing between 2 and 9 solute atoms of $\mathrm{Ti}, \mathrm{Y}$ and $\mathrm{O}$ and were detected for these two conditions. These results support first principle calculations that predicted that vacancies stabilize these Ti-Y-O- clusters, which retard diffusion and contribute to the excellent high temperature stability of the microstructure and radiation tolerance of nanostructured ferritic alloys.
\end{abstract}

\title{
Keywords
}

Solute clusters; nanostructured ferritic alloys; atom probe tomography; single atom detector 


\section{Introduction}

The stability of the microstructure of nanostructured ferritic alloys (NFAs) [1-6] under high temperature creep [7] and high dose radiation damage [9-14] has been attributed to the trapping of vacancies at various microstructural features, thereby minimizing or even preventing solute diffusion [15-17]. Atom probe tomography (APT) $[18,19]$ and transmission electron microscopy have identified several different microstructural features in these ultrafine-grained NFAs that include ultra-fine (1-2 nm diameter) precipitates (often referred to a nanoclusters) in the grain interior, and coarser precipitates, such as pyrochlore and $\mathrm{Ti}(\mathrm{N}, \mathrm{O}, \mathrm{C})$, that are located preferentially on the grain boundaries [20-27]. The grain boundaries also exhibit solute segregation of $\mathrm{Cr}, \mathrm{W}$, and $\mathrm{C}$ atoms $[28,29]$. In addition to these features, the presence of solute clusters, and random solute clusters in the solid solution, could act as vacancy traps and traps for He atoms produced by neutron irradiation [30-33]. The importance of Ti-Y-O clusters in these materials was emphasized by some first principles calculations $[15,16]$ on the binding energies of Ti, Y, $\mathrm{O}$ atoms and vacancies.

However, to date, unambiguously detecting solute clusters in solid solutions has been challenging. The ability to detect solute clusters by APT is strongly influenced by the detection efficiency of the single atom detector and the levels of solutes in solid solution. Although the $\mathrm{Cu}$-Be dynode detector used in the Oxford atom probe field ion microscope [34] provided a detection efficiency of greater than $90 \%$, subsequent commercial variants of atom probes used microchannel plate (MCP) based detectors with much lower detection efficiencies [35]. These commercial variants generally consisted of a pair of MCPs in a chevron configuration and either a phosphor screen or a crossed delay line. Some instruments also included a reflecton lens [36,37] in the time-of-flight mass spectrometer to increase the mass resolution of the instrument. However, reflectrons use a high transmission entrance/exit mesh to define the field gradients, and thereby further reduce the detection efficiency of the instrument by the square of the transmission of this mesh. The resulting detection efficiency of these variants was therefore approximately $40-60 \%$, Therefore, nearest neighbors in the atom probe data were not necessarily nearest 
neighbor atoms in the material. The low detection efficiency also compromised the detection and quantification of solute clusters containing only 2 to $\approx 10$ atoms.

In this paper, a prototype high-detection-efficiency, local electrode atom probe with an estimated detection efficiency of $\sim 80 \%$, together with the analysis of simulated APT data [38], were used to establish the presence of solute clusters in the ferrite phase of a 14YWT NFA. Two far-from-equilibrium conditions of 14YWT have been used. The first was a highly-deformed mechanically-alloyed condition used to produce an essentially precipitate-free solid solution. The second was a highly-deformed material from the stir zone of a friction stir weld that also experienced localized high temperatures during the stirring process. Previous microstructural characterizations of friction stir welds of related oxide dispersion strengthened alloys have been reported [39-46]. The presence of Ti-Y-O solute clusters in these materials will support the predictions of the first principle calculations [15-16]. These solute clusters will also provide an additional microstructural feature for the trapping of vacancies thereby retarding diffusion and contributing to the high stability and radiation tolerance of the microstructure of NFAs at high temperatures.

\section{Simulations}

The feasibility of detecting solute clusters in APT data was evaluated with known structures generated from simulations. Simulated APT data [38] with detection efficiencies (DE) of 40 and $80 \%$ (nominally those of the LEAP 4000X HR and LEAP $5000 \mathrm{XS}$, respectively) were generated for an $\alpha$-Fe crystal structure of the 14YWT nominal composition containing small precipitates and solute clusters. The simulations included small deviations of the atoms from their lattice sites to account for the trajectory aberrations during the field evaporation process. The $30 \mathrm{~nm} \times 30 \mathrm{~nm} \times 30 \mathrm{~nm}$ volumes generated contain 135 clusters with the $\mathrm{A}_{2} \mathrm{~B}_{2} \mathrm{C}_{7}$ stoichiometry of pyrochlore, nominal radii of 0.25 and $0.5 \mathrm{~nm}$ (i.e., corresponding to solutes, and the size of the smallest nanocluster observed in the 14YWT alloy, respectively), and a number density of $5 \times 10^{24} \mathrm{~m}^{-3}$. At $100 \% \mathrm{DE}$, the spherical particles of radius 0.25 
and $0.5 \mathrm{~nm}$ contain on average approximately 5.5 and 43.4 atoms, respectively. As the same seed was used for the random number generator, the precipitates were located in the same positions in each dataset.

Examples of the distribution of the spherical $\mathrm{A}_{2} \mathrm{~B}_{2} \mathrm{C}_{7}$ solute clusters of radius $0.25 \mathrm{~nm}$ within the $30 \mathrm{~nm} \times$ $30 \mathrm{~nm} \times 30 \mathrm{~nm}$ volumes at 80 and $40 \%$ DE with no solute in the matrix are shown in Figs. 1a and 1b, respectively. Thin 2-nm-thick slices extracted from the center of these volumes are shown in Figs. 1c and 1d. The number of solute clusters in the 2 nm-thick sections was reduced from 12 to 9 when the DE was reduced from 80 to $40 \%$ due to the lower number of atoms detected. The corresponding data for 2-nmthick slices with the solute contents of the 14YWT alloy $(0.14 \% \mathrm{~A}, 0.24 \% \mathrm{~B}$ and $0.39 \% \mathrm{C})$ are shown in Figs. 1e and 1f. When the matrix solute atoms are added, it becomes difficult to visually discern which solute clusters are deliberate additions (i.e., those circled in Fig. 1e) and which are due to a combination of compressing the data onto a 2-dimensional plane, and random solute clusters from the matrix solute atoms.

Experimental friends-of-friends (FOF) $[47,18,19]$ data for $40 \%$ and $80 \%$ DE and a maximum separation parameter of $d_{\max }=0.3 \mathrm{~nm}$, and 0.5 -nm-radius particles are compared to versions of the experimental data in which all the mass-to-charge states are randomized in Fig. 2. For the solute-free matrix data, the maximum random solute cluster contained only 3 atoms, and therefore did not interfere with the detected size distribution for the particles. As expected, the average particle size was found to decrease from 43.4 atoms at $100 \% \mathrm{DE}$ to 34.7 atoms and 17.4 atoms at 80 and $40 \% \mathrm{DE}$, respectively. At $80 \% \mathrm{DE}$, the particle distribution was completely separate from the randomized distribution. However, in the $40 \% \mathrm{DE}$ case, there was a significant low-size tail between 2 and 8 atoms in the distribution, which would interfere with the ability to distinguish solute clusters.

The ability to distinguish solute clusters and random solute clusters at $40 \%$ and $80 \%$ DE in solute containing matrices was also investigated by these simulations. By taking the difference of the experimental and randomized distribution, the size distribution of solute clusters can be evaluated, as 
indicated by the solid green line with inverted triangles shown in Fig. 3 which summarizes the results for a $0.77 \%$ solute 14 YWT alloy. For the $40 \%$ DE case, 1 or 2 atom clusters were detected the randomized condition. In the solute free matrix, $71 \%$ of the solute clusters with 2 to 6 atoms were detected, and in the solute-containing case, only $47 \%$ of the clusters containing 3-6 atoms were detected. In contrast in the $80 \%$ DE case, $99 \%$ of the clusters were detected in the solute-free condition, and $90 \%$ were detected in the solute-containing condition.

\section{Experimental}

The material used in this study was a 14YWT nanostructured ferritic alloy (NFA) that was fabricated from a master alloy together with $0.3 \mathrm{wt} \% \mathrm{Y}_{2} \mathrm{O}_{3}$ powder resulting in a nominal composition of $\mathrm{Fe}-15$ at. $\% \mathrm{Cr}, 0.6 \% \mathrm{~W}, 0.26 \% \mathrm{Ti}, 0.13 \% \mathrm{Y}, 0.19 \% \mathrm{O}$ The first material examined was the NFA in the as-milled mechanically-alloyed state. The second condition examined was extracted from the stir zone of a friction stir weld (FSW) that was produced from joining two 14YWT plates that were fabricated from the flakes by hot extrusion at $850{ }^{\circ} \mathrm{C}$, and then aged for $1 \mathrm{~h}$ at $1000^{\circ} \mathrm{C}$. Therefore, the as-milled condition was a highly-deformed solid solution that was far from equilibrium, especially in terms of its vacancy concentration. In contrast, the microstructure of the stir zone before welding consisted of high number densities of nanoclusters and precipitates, which was then highly deformed or sheared by the stirring process and also subjected to local temperatures estimated to be $\approx 1000{ }^{\circ} \mathrm{C}$ followed by a slow cool.

Atom probe tomography specimens were fabricated by a standard focused ion beam lift-out techniques [48] from the as-milled flakes, and the stir zone of the FSW. These specimens were analyzed in a prototype high-detection-efficiency CAMECA Instruments Inc. LEAP 5000 XS instrument with an estimated detection efficiency of approximately $80 \%$. The APT analyses were performed in voltage mode with a specimen temperature of $50 \mathrm{~K}$, a pulse frequency of $200 \mathrm{kHz}$, and a pulse fraction of 0.2 . In order to distinguish the solute clusters from the random clusters due to solute atoms in solid solution, a statistical FOF method was used [47]. A maximum separation parameter of $d_{\max }=0.3 \mathrm{~nm}$ and $\mathrm{Ti}$, TiO, 
$\mathrm{TiO}_{2}, \mathrm{Y}, \mathrm{YO}$, and $\mathrm{O}$ ions were used to detect the solute clusters. No minimum cut off size was used in order to detect the smallest solute cluster.

\section{14YWT NFA results and discussion}

Combined atom maps and concentration isosurfaces of the as-milled flakes and the stir zone of the FSW are shown in Fig. 4. No precipitates were observed in the as-milled flakes; however, some precipitates were observed in the stir zone. The partitioning trends of the solutes between the precipitates and the ferrite are shown in the proximity histogram in Fig. 5. These Ti-, O-, Y-, and Cr-enriched precipitates were excluded from the subsequent analysis of the solute clusters. These precipitates consume some of the available solute atoms so the solute content of the matrix is lower.

A comparison of 1-nm-thick atom maps of the ferrite phase for the as-milled flakes and the stir zone is shown in Fig. 6. The lower solute content in the stir zone is due to the consumption of some solutes in the precipitates. Although some local variations in solute content were observed in the ferrite of the FSW, the overall estimates of the $\mathrm{Ti}+\mathrm{Y}+\mathrm{O}$ solute level in the ferrite phase of the as-milled flakes was $~ 27 \%$ higher than the stir zone. Some selected examples of solute clusters shown by the arrows in Fig. 6 . The differences between the experimental and randomized distributions of the solute cluster sizes for the asmilled flakes and the stir zone are shown in Fig. 7. Coincidentally, both these datasets, each collected from the atoms in two different regions of the bulk material, contained 31.5 million ions. Significant numbers of solute clusters containing between 2 and $9 \mathrm{Ti}, \mathrm{Y}$, and $\mathrm{O}$ atoms were detected in both the asmilled flakes and the stir zone. The majority of the solute clusters contained just 2 or 3 solute atoms. The number densities of solute clusters in the as-miller and stir zone materials were estimated to be $1.8 \pm 1.3$ $\times 10^{24} \mathrm{~m}^{-3}$ and $1.2 \pm 1.1 \times 10^{24} \mathrm{~m}^{-3}$, respectively. Although approximately $55 \%$ more solute clusters per unit volume were observed in the higher solute, as-milled flakes. More solute clusters might be expected in the as-milled condition due to the presence of the precipitates. However, the results were not 
statistically different. Assuming the applicability of the simulations discussed above, both these estimates should be increased to account for the approximately $90 \%$ cluster detection efficiency of this detector.

The presence of these solute clusters will be another source of precipitate hardening, in addition to the standard solid solution hardening mechanism in the ferrite, and precipitate hardening from the intragranular nanoclusters and precipitates. More importantly, the high number densities of the solute clusters will provide another trapping site for vacancies, in addition to the surfaces of the precipitates and the nanoclusters. Vacancy trapping will reduce the diffusion of the solute atoms, and thereby be a factor contributing to the excellent stability of the microstructure of NFAs from coarsening at high temperatures and high doses. The solute clusters may also be a trapping site for the helium atoms produced during neutron irradiation and may explain the relatively high matrix solubility of helium that has recently been measured in helium-injected NFAs [30].

\section{Conclusions}

Atom probe tomography FOF analysis of the simulated 14YWT data indicated that solute clusters should be resolvable above the random solutes in data produced by local electrode atoms probes with detection efficiencies of at least $80 \%$. High number densities, $1.8 \times 10^{24} \mathrm{~m}^{-3}$ and $1.2 \times 10^{24} \mathrm{~m}^{-3}$, respectively, of solute clusters containing between 2 and $9 \mathrm{Ti}, \mathrm{Y}$, and $\mathrm{O}$ atoms were detected in a local electrode atom probe with an estimated detection efficiency of approximately $80 \%$ in both the as-milled flakes and the stir zone. These solute clusters will provide another trapping site for vacancies which will reduce the diffusion of the solute atoms, and thereby be a factor in the excellent stability of the microstructure of NFAs from coarsening at high temperatures and high doses.

\section{Acknowledgements}

This work was supported by the U.S. Department of Energy, Office of Science, Basic Energy Sciences, Materials Sciences and Engineering Division. Atom probe tomography was conducted at the Center for Nanophase Materials Sciences, which is a DOE Office of Science User Facility. The authors thank Drs. 
X. Yu and Z. Feng for producing the friction stir weld, and Dr. D. T. Hoelzer for supplying the 14YWT material.

\section{References}

[1] R.L. Klueh, J. Nucl. Mater., 378(2) (2008) 159-166.

[2] K.L. Murty, I. Charit, J. Nucl. Mater., 383 (2008) 189-195.

[3] G.R. Odette, M.J. Alinger, B.D. Wirth, Annual Review of Materials Research, 38 (2008) 471-503.

[4] R.K. Nanstad, D.A. McClintock, D.T. Hoelzer, L. Ta, T.R. Allen, J. Nucl. Mater., 392(2) (2009) $331-340$.

[5] Y. Guerin, G.S. Was, S.J. Zinkle, MRS Bulletin, 34(1) (2009) 10-14.

[6] G.R. Odette, D.T. Hoelzer, JOM, 62(9) (2010) 84-92.

[7] J.H. Schneibel, C.T. Liu, M.K. Miller, M.J. Mills, P. Sarosi, M. Heilmaier and D. Sturm, Scr. Mater., 61(8) (2009) 793-796.

[8] D.A. McClintock, M.A. Sokolov, D.T. Hoelzer, R.K. Nanstad, J. Nucl. Mater., 392 (2009) 353-359.

[9] M.K. Miller, D.T. Hoelzer, K.F. Russell, Mater. Sci. Forum, 654-656 (2010) 23-28.

[10] A.G. Certain, K.G. Field, T.R. Allen, M.K. Miller, J. Bentley, J. Busby, J Nucl. Mater., 407(1) (2010) 2-9.

[11] M.K. Miller, D.T. Hoelzer, J. Nucl. Mater., 418 (2011) 307-310.

[12] M K. Miller, Y. Zhang, Ultramicroscopy, 111 (2011) 672-675.

[13] C.M. Parish, R.M. White, J.M. LeBeau, M.K. Miller, J. Nucl. Mater., 445 (2014) 251-260.

[14] C.M. Parish, P.D. Edmondson, Y. Zhang, M.K. Miller, J. Nucl. Mater., 418 (2011) 106-109.

[15] C.L. Fu, M. Krcmar, G.S. Painter, X.-Q.Chen, Phys. Rev. Lett., 97 (2007) 225502.

[16] M.K. Miller, C.L. Fu, M. Krcmar, D.T. Hoelzer, C.T. Liu, Front. Mater. Sci. China, 3(1) (2009) 914. 
[17] J. Xu, C.T. Liu, M.K. Miller, H. Chen, Phys. Rev. B, 79 (2009) 020204-1-4 DOI: 10.1103/PhysRevB.79.020204.

[18] D.J. Larson, T.J. Prosna, R.M. Ulfig, B.P. Geiser, T. F. Kelly, Local Electrode Atom Probe Tomography, Springer, New York NY, 2013.

[19] M.K. Miller, R. G. Forbes, Atom Probe Tomography: The Local Electrode Atom Probe, Springer, New York NY, 2014.

[20] D.J. Larson, P.J. Maziasz, I.-S. Kim, K. Miyahara, Scr. Mater., 44 (2001) 359-364.

[21] M.K. Miller, E.A. Kenik, K.F. Russell, L. Heatherly, D.T. Hoelzer, P.J. Maziasz, Mater. Sci. Eng. A., A353 (2003) 140-145.

[22] M.K. Miller, K.F. Russell, D.T. Hoelzer, J. Nucl. Mater., 351 (2006) 261-268.

[23] M.J. Alinger, G.R. Odette, D.T. Hoelzer, Acta Mater., 57(2) (2009) 392-406.

[24] M.K. Miller, D.T. Hoelzer, K.F. Russell, Mater. Sci. Forum, 654-656 (2010) 23-28.

[25] M.K. Miller, C.M. Parish, Mater. Sci. Technol., 27 (2011) 729-734

[26] M.C. Brandes, L. Kovarik, M.K. Miller, M.J. Mills, J. Mater. Sci., 47 (2012) 3913-3923.

[27] M.K. Miller, C.M. Parish, Q. Li, Mater. Sci. Technol., 29(10) (2013) 1174-1178.

[28] L. Yao, S.P. Ringer, J.M. Cairney, M.K. Miller, Scr. Mater., 69(8) (2013) 622-5.

[29] M.K. Miller, L. Yao, Current Opinions in Solid State and Materials Science, 17 (2013) 203-210.

[30] Q. Li, C.M. Parish, K.A. Powers, M. K. Miller, J. Nucl. Mater., 445(1-3) (2014) 165-174.

[31] P.D. Edmondson, C.M. Parish, Y. Zhang, A. Hallén, M.K. Miller, J. Nucl. Mater., 434(1-3) (2013) 210-216.

[32] P.D. Edmondson, C.M. Parish, Y. Zhang, A. Hallén, M.K. Miller, Scr. Mater., 65(8) (2011) 731 734.

[33] C.M. Parish, M.K. Miller, Microsc. Microanal., 20(2) (2014) 613-626.

[34] M.K. Miller, P.A. Beaven and G.D.W. Smith, Surf. Interface Anal., 1 (1979) 149-60.

[35] M. K. Miller, Atom Probe Tomography: Analysis at the atomic level, Springer, New York, NY, 2000, pp. 99-117.

[36] B.A Mamyrin, V.I. Karataev, D.V. Shmikk, V.A. Zagulin, Soviet Phys. JEPT, 37 (1973) 45-48. 
[37] P. Panayi, U.S. patent No. 11/913,343, 2007.

[38] M.K. Miller, J.M. Hyde, In: 11th Euro. Congr. Electron Microscopy, Dublin, Ireland, CD, August 1996.

[39] B.J. Inkson, P.L. Threadgill, Mater. Sci. Eng. A, 258(1) (1998) 313-318.

[40] H. Ates, M. Turker, A. Kurt, Mater. Design, 28(3), (2007) 948-953.

[41] M.H. Mathon, V. Klosek, Y. De Carlan, L. Forest, J. Nucl. Mater., 386 (2009)475-478.

[42] F. Legendre, S. Poissonnet, P. Bonnaillie, L. Boulanger, L. Forest, J. Nucl. Mater., 386 (2009) 537 539.

[43] C.L. Chen, G.J. Tatlock, A. R. Jones, J. Alloys and Compounds, 504 (2010) S460-S466.

[44] S. Noh, R. Kasada, A. Kimura, S.H.C. Park, S. Hirano, S, J. Nucl. Mater., 417(1) (2011) 245-248.

[45] J. Wang, W. Yuan, R.S. Mishra, I. Charit, J. Nucl. Mater., 432(1) (2013) 274-280.

[46] D.T. Hoelzer, K.A. Unocic, M.A. Sokolov, Z. Feng, J. Nucl. Mater., 442(1) (2013) S529-S534.

[47] J.M. Hyde, C.A. English, MRS Symp. Proc., Boston, MA, 650 (2000) R6.6.

[48] K. Thompson, D.J. Lawrence. D.J. Larson, J.D. Olson, T.F. Kelly, B. Gorman, Ultramicroscopy, 107 (2007) 131-9. 


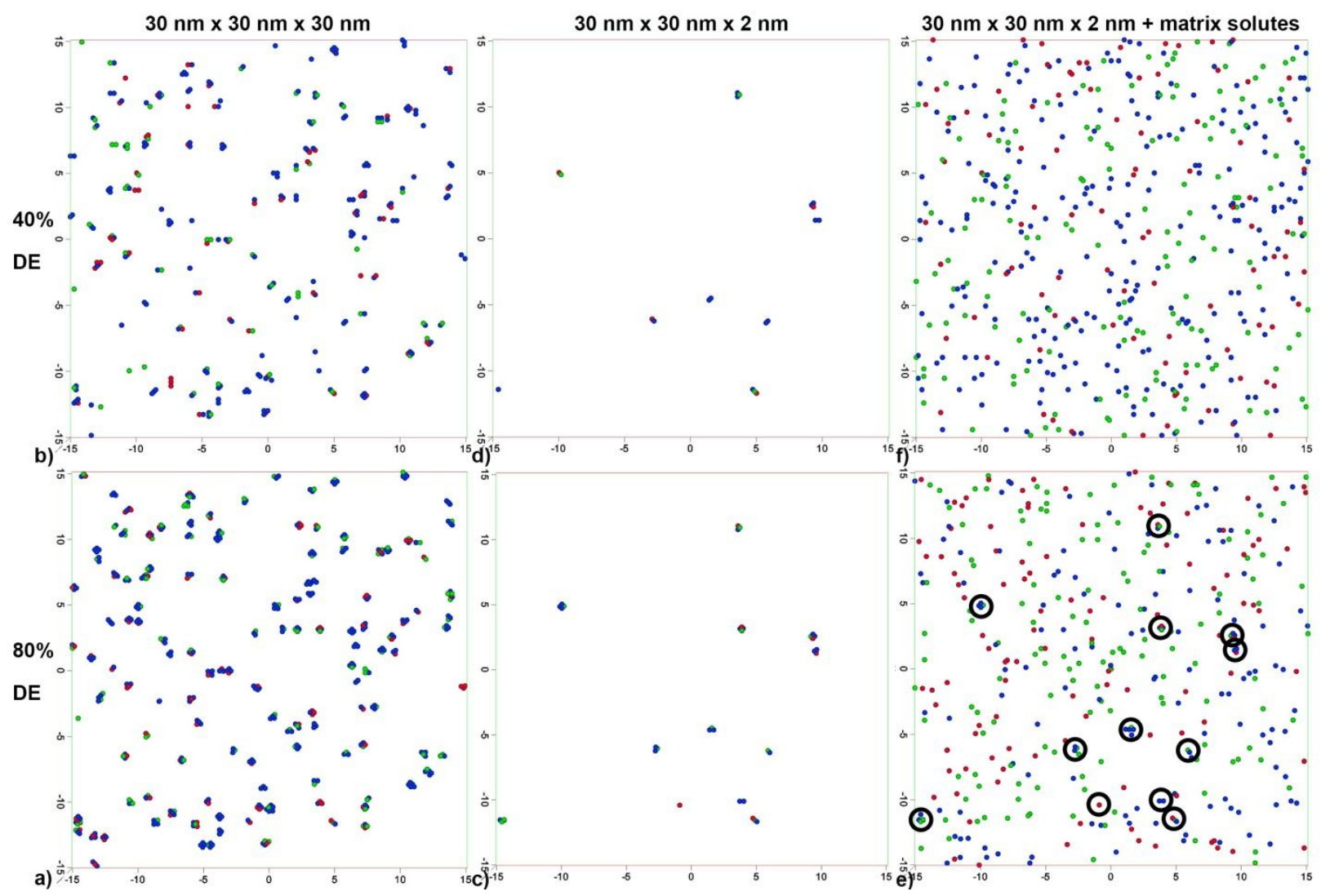

Fig. 1. Atom maps of simulated APT data with $40 \%$ and $80 \%$ detection efficiencies with spherical particles of radius $0.25 \mathrm{~nm}$ containing on average approximately 5.5 atoms. 


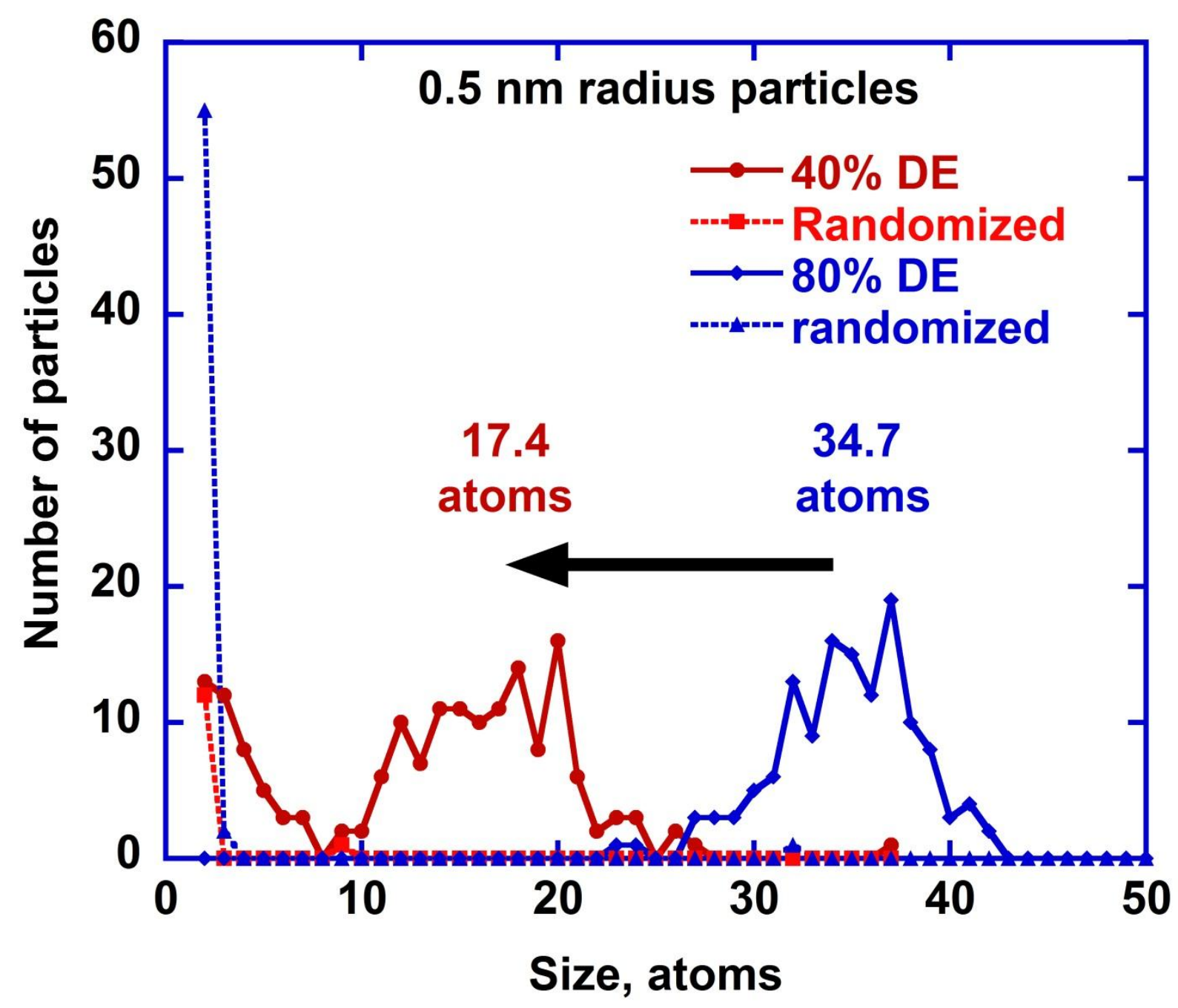

Fig. 2. Effect of detection efficiency on the number of particles detected with different number of atoms. The measured particle distribution moves to lower sizes and interferes with the random solute clusters at lower detection efficiencies. 

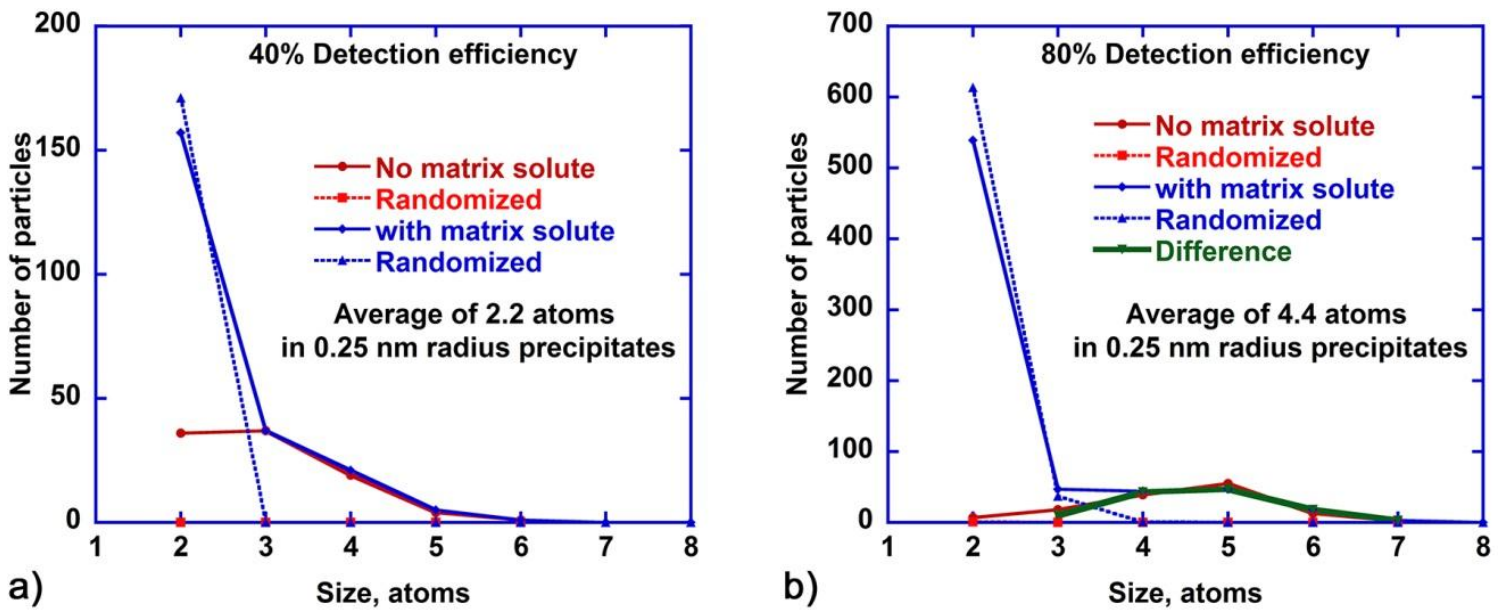

Fig. 3. Effect of detection efficiency on the ability to detect $0.25-\mathrm{nm}$-radius solute clusters each containing on average 5.5 atoms with and without any solute atoms in the matrix. 


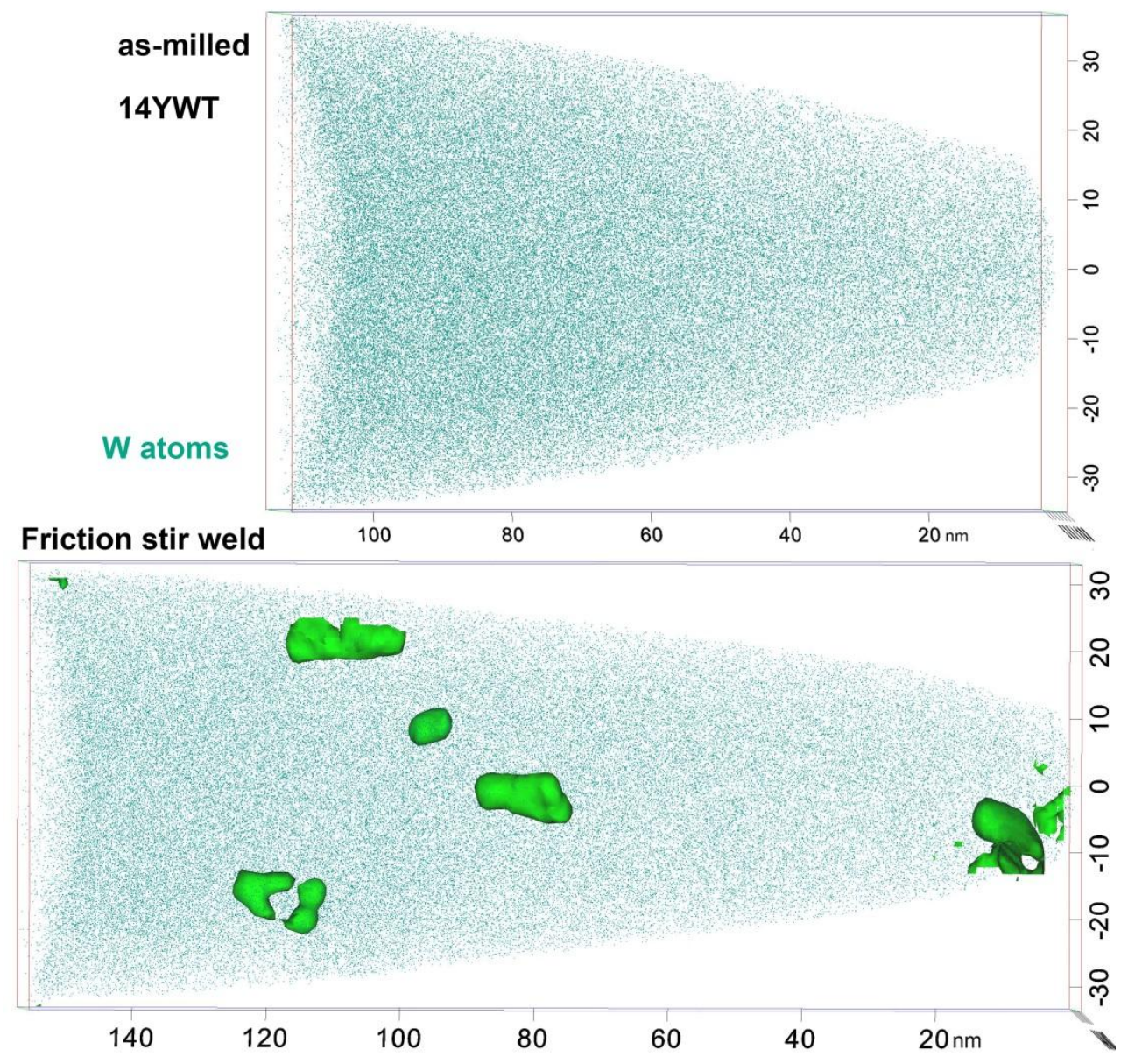

Fig. 4. The fine-scale microstructures of the as-milled flakes and the stir zone of a 14YWT NFA. No precipitates were observed in the as-milled state but were observed in the stir zone, as indicated by the $2 \% \mathrm{TiO}$ concentration isosurfaces. $\mathrm{W}$ atoms are used to show the extents of the volumes of analysis. 


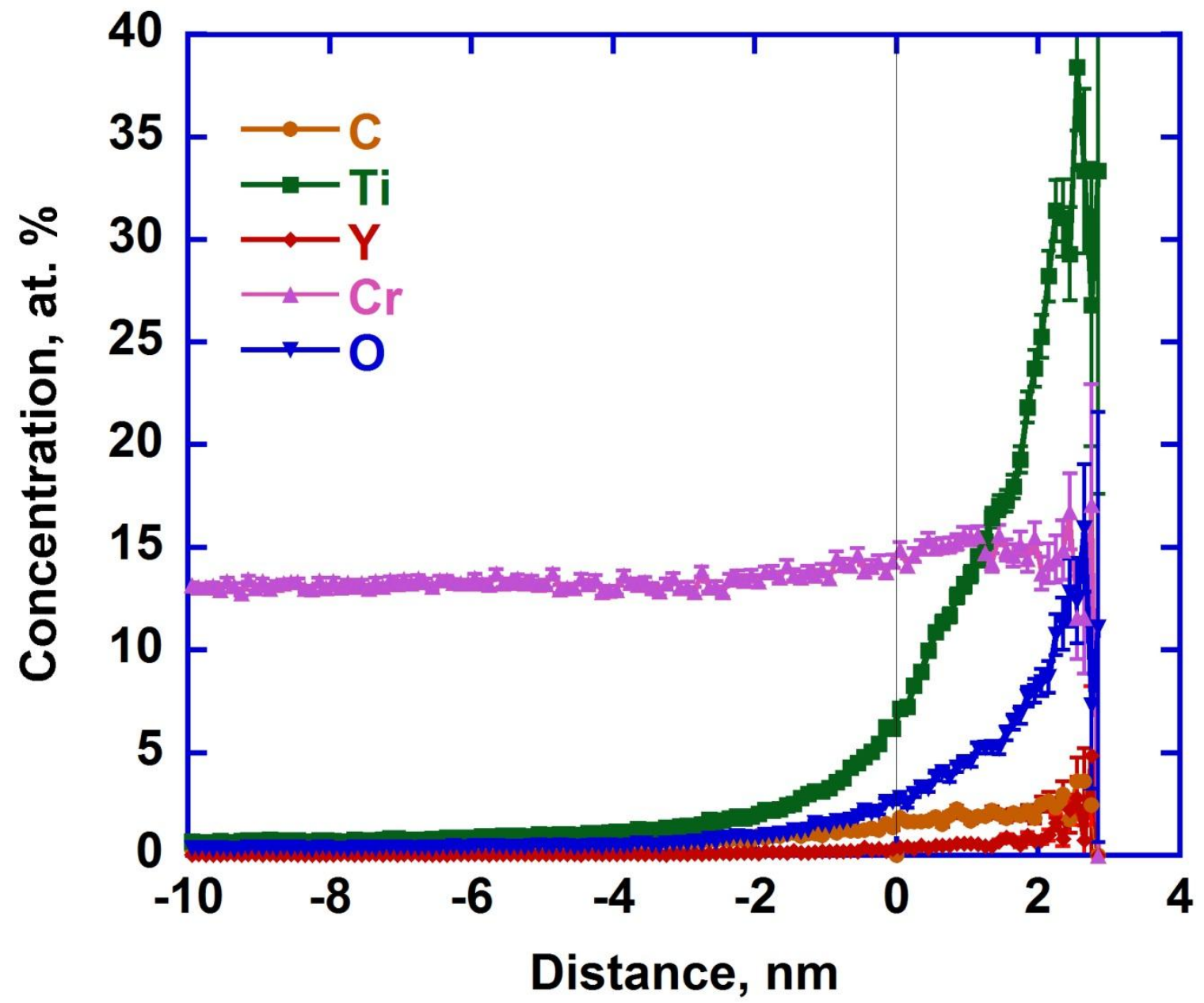

Fig. 5. Proximity histogram of the solute partitioning between the Ti, $\mathrm{O}, \mathrm{Y}$, and $\mathrm{C}$ enriched precipitates and ferrite matrix in the stir zone of the friction stir weld. 


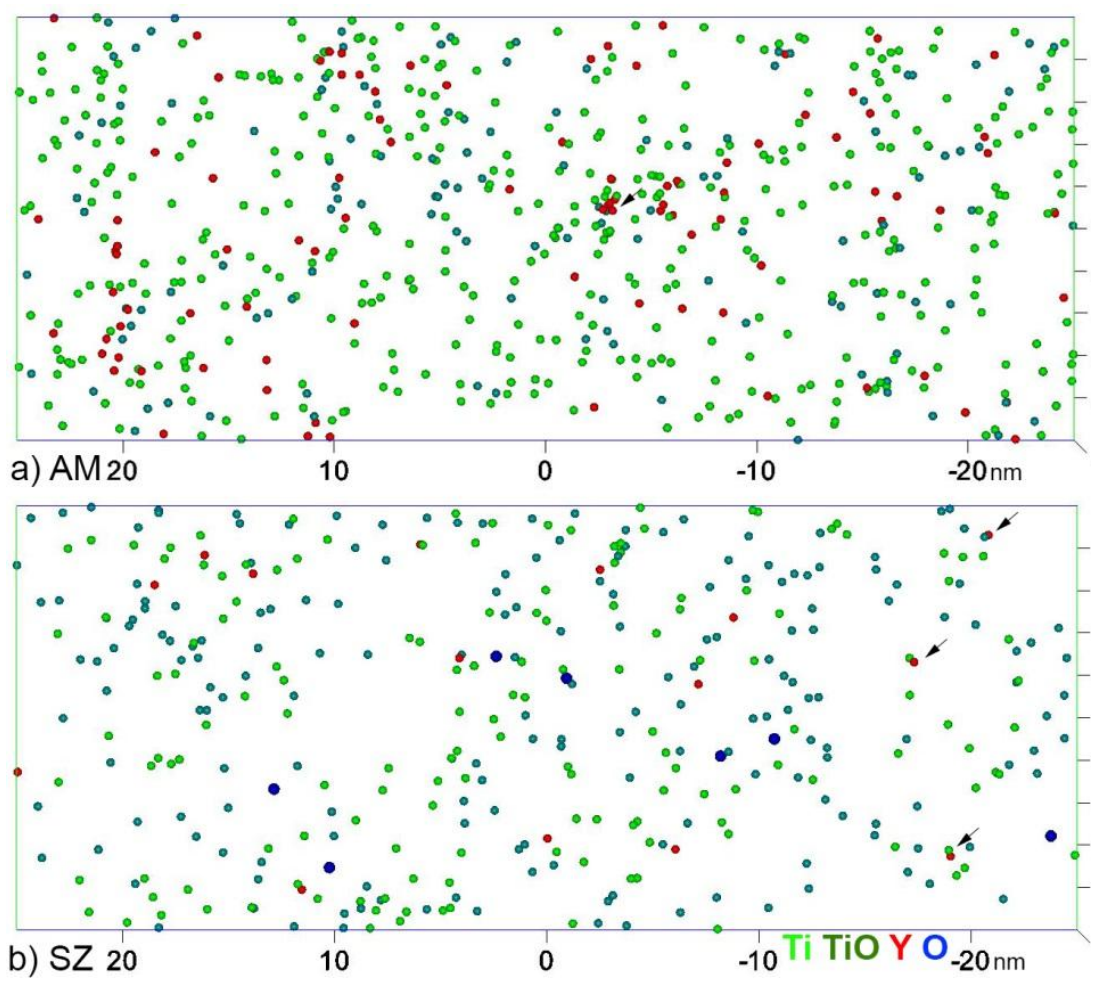

Fig. 6. 1-nm-thick Ti, TiO, $\mathrm{Y}$ and $\mathrm{O}$ atom maps of the as-milled flakes and the stir zone of the fraction stir weld. The arrows denote some of the solute clusters. 


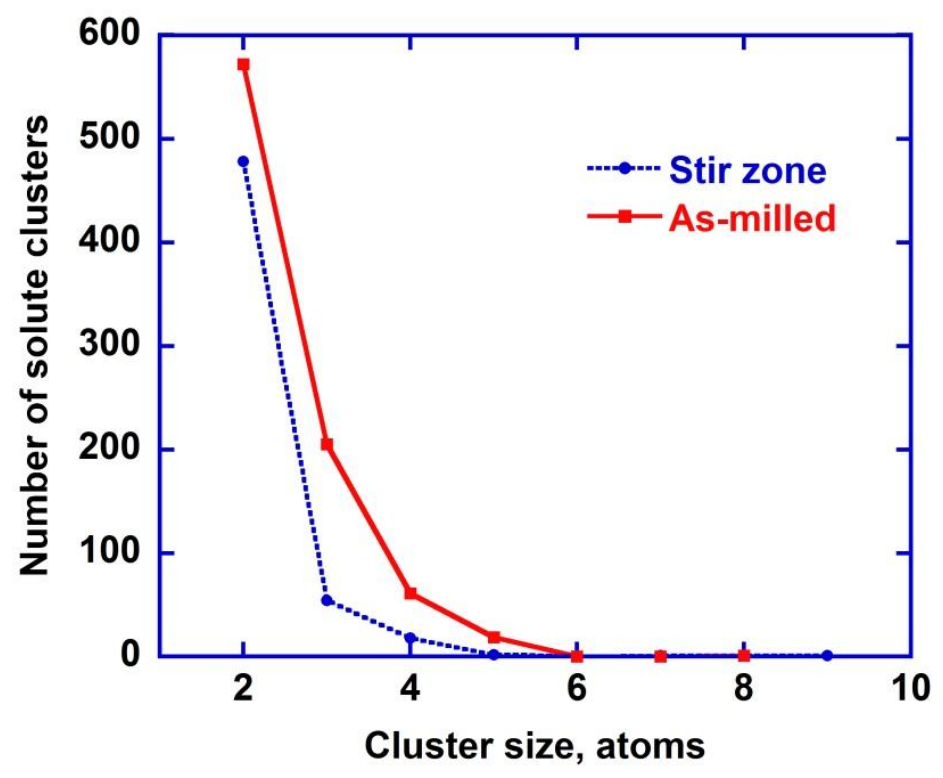

Fig. 7. The number of solute clusters (experimental minus randomized condition of the Ti, TiO, TiO2, Y, $\mathrm{YO}$, and $\mathrm{O}$ ions) detected as a function of the cluster size in the as-milled condition and the stir zone of a 14YWT NFA. More solute clusters were detected in the as-milled condition. 